\title{
Comparative efficacy of early morning versus bedtime administration of levothyroxine in children with hypothyroidism: a prospective, open label, randomized, case-control study
}

Porównanie skuteczności podawania lewotyroksyny rano i przed snem u dzieci z niedoczynnością tarczycy: prospektywne, otwarte, badanie kontrolne z randomizacją

\author{
${ }^{1}$ Azhar Navid, ${ }^{2}$ Devi Dayal, ${ }^{3}$ Harvinder Kaur, ${ }^{2}$ Atul Gupta, ${ }^{1}$ Savita V. Attri
}

${ }^{1}$ Department of Pediatrics, Postgraduate Institute of Medical Education and Research, Chandigarh, India ${ }^{2}$ Endocrinology and Diabetes Unit, Department of Pediatrics, Postgraduate Institute of Medical Education and Research, Chandigarh, India

${ }^{3}$ Growth and Anthropology Unit, Department of Pediatrics, Postgraduate Institute of Medical Education and Research, Chandigarh, India

\begin{abstract}
Introduction: Studies in adults with hypothyroidism suggest an equal efficacy of bedtime versus early morning intake of levothyroxine. There is limited data on timing of levothyroxine administration in children.

Methods: Children with hypothyroidism on early morning levothyroxine, and clinically and biochemically euthyroid, were assigned to receive levothyroxine at bedtime (group A) or were continued on early morning levothyroxine intake (group B). Clinical, anthropometric and laboratory evaluation (thyroid and lipid profiles, liver enzymes and creatinine) was done at baseline, and at 3 and 6 months. Results: Eighty-four children, 42 in each group, completed the study. The clinical and anthropometric parameters remained similar in the two groups at baseline and at 3- and 6-month follow-up visits. There was no difference in the mean serum concentrations of triiodothyronine, thyroxine and thyrotropin at the 3 time-points in the study. In addition, mean serum aspartate transaminase, alanine transaminase, creatinine and parameters of lipid profiles remained similar in the two groups. The requirement of levothyroxine was similar at baseline $(48.6 \pm 16.9 \mu \mathrm{g}$ vs. $49.6 \pm 19.5 \mu \mathrm{g}, p$-value 0.80$)$ and at the endpoint $(48.3 \pm 17.2 \mu \mathrm{g}$ vs. $51.9 \pm 18.0 \mu \mathrm{g}, p$-value 0.46$)$ in both groups. At the study end, 25 (60\%) patients in group A and 17 (40\%) in group B preferred bedtime dosing of levothyroxine. Conclusions: We found an equal efficacy of bedtime intake compared to early morning intake of levothyroxine in maintaining an euthyroid state in children with hypothyroidism. Further studies are required to see if bedtime levothyroxine administration improves the quality of life of patients.
\end{abstract}

Key words:

hypothyroidism, levothyroxine, early morning intake, bedtime intake, children.

\section{Introduction}

Hypothyroidism, whether congenital or acquired, is one of the most common endocrine conditions in pediatric practice [1]. Congenital hypothyroidism occurs in $1: 1500$ to $1: 3000$ live births whereas acquired hypothyroidism has a prevalence of $1-2 \%$ in the pediatric population $[1,2]$. The treatment of hypothyroidism consists of a life-long daily administration of levothyroxine which is traditionally taken orally in early morning at least 30-60 minutes before breakfast [2-4]. The empty stomach intake of levothyroxine is considered to be an effective longterm treatment of hypothyroidism due presumably to its better absorption in the fasting state as compared to a non-fasting state [2]. The early morning administration also helps to avoid several other factors that may interfere in its absorption [5]. Understandably, the consensus guidelines formulated by several prominent international pediatric endocrine societies emphasize on adherence to empty stomach administration of levothyroxine in children [6].

Practically however, keeping the desired time gap between levothyroxine intake and food intake during morning hours may be difficult for patients with unpredictable or variable morning schedules that cause problems of compliance with standard recommendations $[2,6]$. For school going children, the early
$178 \quad$ Prof. Devi Dayal Endocrinology and Diabetes Unit, Department of Pediatrics Advanced Pediatrics Center Postgraduate Institute of Medical Education and Research
Chandigarh-160012, India

tel. 0091-172-2755657 (O) 0091-172-2772777 (R) fax 0091-172-2744401; 2745078 e-mail: drdevidayal@gmail.com; dayal.devi@pgimer.edu.in 
school start times put extra pressure on their morning routines [7]. The distancing of levothyroxine administration from food intake is often impossible due to rushed morning routines and may result in poor control of hypothyroid state [8]. Although new pre-dissolved formulations such as soft gel or liquid levothyroxine may allow co-ingestion with food, the evidence for their use in clinical practice is weak [9]. In addition, the new formulations are not widely available. Alternative schedules of levothyroxine administration have, therefore, been suggested to improve compliance to therapy of hypothyroidism $[10,11]$.

Of all the alternative schedules, the evening or bedtime administration of levothyroxine appears to be an attractive option [12]. It offers several advantages such as the ease to maintain the required time gap between levothyroxine and food intake, choice of timing, convenience, and an improvement in adherence to therapy and the quality of life (QoL) $[12,13]$. In addition, the bedtime administration is presumed to have better bioavailability and absorption from the gut [11]. Several studies have indeed been conducted on bedtime or evening-time dosing of levothyroxine in patients of hypothyroidism over the past two decades [14]. A meta-analysis of 10 studies that compared the effect of levothyroxine administration before breakfast to administration at bedtime found no association with serum concentrations of thyroid stimulating hormone (TSH) or free triiodothyronine (FT3) in patients with hypothyroidism [15]. The bedtime administration showed better free thyroxine (FT4) concentrations [15]. The meta-analysis concluded that administration of levothyroxine at bedtime is as effective as administration before breakfast for patients with hypothyroidism [15]. However, a majority of the studies included in the meta-analysis were conducted on adult or elderly patients with hypothyroidism [15]. The only pediatric study included in the meta-analysis was conducted on school children with acquired hypothyroidism and the effect of shifting to bedtime dosing was studied over a short duration of 3 months [13]. Another recent study on bedtime intake of levothyroxine in children also evaluated its short-term efficacy only [16]. Nevertheless, both these studies showed that shifting the levothyroxine administration to bedtime was beneficial in the short term $[13,16]$. The longer-term effectiveness of bedtime levothyroxine intake, however, remains unevaluated in children with hypothyroidism. We therefore planned to study the efficacy of bedtime dosing of levothyroxine in maintaining an euthyroid state, and whether the shift in timing from early morning to bedtime is associated with any adverse effects at the tissue level over a longer duration.

\section{Material and methods}

The study was conducted in the Endocrinology Clinic of a large pediatric tertiary care teaching hospital located in Northwest India from January 2019 to June 2020. Children of either sex, aged between 4 and 12 years and diagnosed with either congenital or acquired hypothyroidism were enrolled into the study if they were clinically and biochemically euthyroid for at least 6 months and had no other known endocrinopathy. Inability to come for regular follow up visits, problems with adher- ence to medications in the past, and intake of drugs known to interfere with thyroxine metabolism e.g.; antiepileptics, were the exclusion criteria.

After recruitment into the study, children were assigned to receive levothyroxine (oral tablets) at bedtime (group $A$, study group) or were continued with their early morning levothyroxine (oral tablets) dosing (group B, control group). The allocation to either group was done by a computer generated random number table. The time gap between dinner and levothyroxine administration was at least one hour.

At inclusion, all children underwent a thorough clinical assessment specifically targeted at symptoms and signs of hypo- or hyperthyroid state. The anthropometric evaluation comprised of recording weight $(\mathrm{kg})$ and height $(\mathrm{cm})$, and calculation of body mass index (BMI) as $\mathrm{kg} / \mathrm{m}^{2}$. Laboratory evaluation consisted of estimation of serum concentrations of total T3, total T4, TSH, total cholesterol (TC), total triglyceride (TG), high-density lipoprotein cholesterol (HDL-C), low-density lipoprotein cholesterol (LDL-C), serum creatinine, aspartate (AST) and alanine transaminase (ALT). All children were followed up at 3 monthly intervals for 6 months. At the follow up visit, each patient underwent clinical, anthropometric and laboratory evaluation. Adjustments in levothyroxine doses in both groups were done as per the previous routine to keep serum concentrations of total T4 in upper half of normal range and TSH in low normal range. No change in the levothyroxine formulation and route of administration was allowed throughout the study period. The study was approved by the Institute's Ethics Committee.

\section{Statistical analysis}

The data were analysed using Statistical Package for the Social Sciences (SPSS, version 23.0, IBM Corp., Armonk, NY, USA). The continuous data was first checked for its normalcy by Kolmogorov Smirnov test. For normally distributed data, the comparison between study and control group was made by Student's $t$-test. For skewed data, the distribution of the two groups was compared using Mann-Whitney test. McNemar test was applied for the significance of changes from visit to visit. Repeated measure ANOVA was applied to find the trend of the measurable data over visits. A $p$-value of less than 0.05 was considered significant.

\section{Results}

The study population comprised of 84 children; each group had 42 children. The mean age in the two groups was similar (7.6 \pm 2.3 year vs. $7.1 \pm 3.1$ year, $p=0.43)$. Two thirds $(n=28)$ were girls in each group. A majority of patients ( $n=57,67.8 \%)$ had acquired hypothyroidism; the proportion of children with acquired hypothyroidism was more $(80.9 \%, 34$ out of 42$)$ in group A as compared to group B (54.7\%, 23 out of 42).

At follow-up visits, no patient in either group showed any hypo- or hyperthyroid symptoms such as changes in sleep, appetite, sweating, activity, stooling pattern etc. There was no difference in the mean BMI in the two groups at inclusion (14.8 \pm 6.5 vs. $16.1 \pm 8.3, p=0.53)$ and at the study endpoint 
Table I. Laboratory characteristics of study population at different time-points during the study

\begin{tabular}{|c|c|c|c|c|}
\hline Variables & Time-point & $\begin{array}{l}\text { Group A }(n=42) \\
(\text { mean } \pm S D)\end{array}$ & $\begin{array}{l}\text { Group B }(n=42) \\
(\text { mean } \pm S D)\end{array}$ & $P$-value \\
\hline \multirow[t]{3}{*}{ Triiodothyronine (ng/ml) } & Baseline & $1.40 \pm 0.44$ & $1.31 \pm 0.38$ & 0.36 \\
\hline & 3 months & $1.45 \pm 0.39$ & $1.34 \pm 0.43$ & 0.21 \\
\hline & 6 months & $1.33 \pm 0.49$ & $1.20 \pm 0.31$ & 0.14 \\
\hline \multirow[t]{3}{*}{ Thyroxine ( $\mu \mathrm{g} / \mathrm{dl})$} & Baseline & $9.01 \pm 2.91$ & $9.45 \pm 2.43$ & 0.45 \\
\hline & 3 months & $9.05 \pm 2.03$ & $9.71 \pm 1.90$ & 0.12 \\
\hline & 6 months & $9.12 \pm 1.65$ & $8.89 \pm 1.97$ & 0.56 \\
\hline \multirow[t]{3}{*}{ Thyroid stimulating hormone (mIU/l) } & Baseline & $3.39 \pm 2.75$ & $3.40 \pm 2.08$ & 0.98 \\
\hline & 3 months & $3.52 \pm 2.04$ & $3.41 \pm 1.92$ & 0.78 \\
\hline & 6 months & $3.56 \pm 2.16$ & $3.77 \pm 2.16$ & 0.65 \\
\hline \multirow[t]{3}{*}{ Aspartate transaminase $(\mathrm{U} / \mathrm{l})$} & Baseline & $31.50 \pm 7.24$ & $31.20 \pm 7.90$ & 0.85 \\
\hline & 3 months & $29.77 \pm 6.73$ & $29.91 \pm 6.67$ & 0.92 \\
\hline & 6 months & $30.65 \pm 9.25$ & $31.47 \pm 7.21$ & 0.65 \\
\hline \multirow[t]{3}{*}{ Alanine transaminase $(\mathrm{U} / \mathrm{l})$} & Baseline & $31.09 \pm 7.41$ & $29.83 \pm 8.24$ & 0.46 \\
\hline & 3 months & $31.71 \pm 6.81$ & $29.57 \pm 6.81$ & 0.15 \\
\hline & 6 months & $32.37 \pm 6.85$ & $29.18 \pm 7.57$ & 0.06 \\
\hline \multirow[t]{3}{*}{ High-density lipoprotein cholesterol (mg/dl) } & Baseline & $51.48 \pm 13.16$ & $47.61 \pm 9.12$ & 0.07 \\
\hline & 3 months & $52.39 \pm 11.04$ & $48.46 \pm 7.50$ & 0.07 \\
\hline & 6 months & $51.69 \pm 10.96$ & $48.65 \pm 8.34$ & 0.15 \\
\hline \multirow[t]{3}{*}{ Low-density lipoprotein cholesterol (mg/dl) } & Baseline & $96.87 \pm 17.54$ & $96.87 \pm 17.64$ & 0.45 \\
\hline & 3 months & $96.90 \pm 18.06$ & $96.77 \pm 14.56$ & 0.97 \\
\hline & 6 months & $97.68 \pm 16.19$ & $97.73 \pm 17.38$ & 0.99 \\
\hline \multirow[t]{3}{*}{ Triglycerides (mg/dl) } & Baseline & $87.26 \pm 14.18$ & $91.21 \pm 11.00$ & 0.15 \\
\hline & 3 months & $86.16 \pm 15.57$ & $91.22 \pm 11.55$ & 0.09 \\
\hline & 6 months & $87.86 \pm 15.99$ & $93.18 \pm 11.26$ & 0.07 \\
\hline \multirow[t]{3}{*}{ Total cholesterol (mg/dl) } & Baseline & $158.07 \pm 18.84$ & $165.91 \pm 15.33$ & 0.40 \\
\hline & 3 months & $155.14 \pm 15.73$ & $165.49 \pm 13.06$ & 0.21 \\
\hline & 6 months & $156.90 \pm 17.99$ & $162.99 \pm 17.06$ & 0.11 \\
\hline \multirow[t]{3}{*}{ Serum creatinine (mg/dl) } & Baseline & $0.35 \pm 0.10$ & $0.33 \pm 0.10$ & 0.37 \\
\hline & 3 months & $0.47 \pm 0.77$ & $0.34 \pm 0.09$ & 0.29 \\
\hline & 6 months & $0.36 \pm 0.09$ & $0.34 \pm 0.90$ & 0.42 \\
\hline
\end{tabular}


(17.4 \pm 8.1 vs. $17.8 \pm 8.8, p=0.70)$. The laboratory parameters of the study population at baseline, and at the time of follow-up visits are shown in Table I. The requirement of levothyroxine was similar at baseline $(48.6 \pm 16.9 \mu \mathrm{g}$ vs. $49.6 \pm 19.5 \mu \mathrm{g}, p=0.80)$ and at the endpoint $(48.3 \pm 17.2 \mu \mathrm{g} v \mathrm{~s} .51 .9 \pm 18.0 \mu \mathrm{g}, p=0.46)$ in both groups. There were no dropouts from the study. At the end of the study, 25 (60\%) patients in group A and 17 (40\%) in group B showed their preference for bedtime dosing of levothyroxine.

\section{Discussion}

The results of our study indicate that the intake of levothyroxine at bedtime was as efficacious as the early morning intake in maintaining an euthyroid status in children with hypothyroidism. The results are consistent with the only two previous studies in children $[13,16]$. Similar efficacy of bedtime levothyroxine has also been demonstrated in several studies in adults [15]. However, two previous studies in adult patient populations of hypothyroidism found a slightly lower efficacy of levothyroxine when administered in a non-fasting state $[17,18]$. In one such study by Bach-Huynh et al., serum TSH concentrations were found to be more variable and higher when levothyroxine was taken at bedtime but still remained in the normal range at most occasions $(2.19 \pm 2.66 \mathrm{mlU} / \mathrm{l})$. The authors suggested that fasting ingestion of levothyroxine should be advised when a specific serum TSH goal is desired [17]. Specific serum TSH goal is usually desirable during initial 3-4 years of age to avoid any compromise with early brain growth and other developmental issues $[6,19,20]$. For this reason, we did not include children below 4 years of age. In another study, the therapeutic efficacy of levothyroxine was shown to decrease slightly when the timing of intake was shifted to before dinner [18]. However, maintaining a gap of at least one hour between dinner and levothyroxine administration probably helped to maintain the efficacy of levothyroxine in our patients.

Similar to observations by others, we also found a tendency towards better serum T4 concentrations as well as a tendency towards a lower levothyroxine requirement in patients taking bedtime levothyroxine $[13,16]$. Both these findings, however, did not reach statistical significance. The slightly higher serum T4 concentrations in patients on bedtime levothyroxine may be explained by a better absorption of levothyroxine [5]. Levothyroxine absorption is enhanced by a lower gastric pH probably by an alteration in the ionization of the levothyroxine sodium salt in an acidic environment $[5,11]$. The gastric acid secretion is greater in the evening than in the morning and reaches its circadian peak during the night-time [21]. In addition, decreased gastrointestinal movement during night time may also contribute to higher serum T4 concentrations [16]. A shorter time interval between bedtime levothyroxine and blood collection for thyroid testing is also thought to result in some increase the serum T4 concentrations in patients on bedtime levothyroxine. However, levothyroxine pharmacokinetic studies indicate that the serum T4 concentrations remain constant for upto 50 hours following an initial peak between 4 and 6 hours of oral levothyroxine intake [22].

A reassuring finding in our study was the lack of adverse effects of shifting of levothyroxine timing at the tissue level, as reflected by normal serum concentrations of liver enzymes, lipids and creatinine at the follow-up visits. Elevation of liver enzymes, specifically ALT, is a marker of uncontrolled hypothyroidism [23, 24]. Similarly, dyslipidemia, is often a reflection of poor control of hypothyroid state even when the serum TSH is apparently in the normal ranges [25-27]. An increase in serum creatinine and a decrease in glomerular filtration rate is also associated with hypothyroid state [28]. The finding that all these markers of hypothyroid state remained normal in children on bedtime levothyroxine, is therefore important, and reflects the efficacy of this schedule in maintaining an euthyroid state even at the tissue level. The concerns that the timing of levothyroxine administration may affect the TSH circadian rhythm, have been addressed in earlier studies [11].

There are two limitations of our study. First, the recruitment of patients had to be prematurely stopped due to the onset of COVID-19 pandemic, and the announcement of a nationwide lockdown since March 25, 2020 that severely disrupted the non-COVID-19 patient care services at our hospital [29]. The submission of research work was time-bound as it was the thesis project of a postgraduate student, limiting the sample size to 42 and not the originally planned 63 in each group. Secondly, we did not perform the QoL studies, although majority of the parents and patients expressed their preference to continue with the bedtime schedule. Nevertheless, our study adds to the scarce literature on bedtime dosing of levothyroxine in children, and helps to assure the practicing pediatricians and pediatric endocrinologists to alter their levothyroxine prescriptions confidently. To best of our knowledge, our study is the longest observation on the bedtime administration of levothyroxine in children with hypothyroidism.

In conclusion, the administration of levothyroxine at bedtime was found to be as efficacious as the traditional administration before breakfast in maintaining an euthyroid state in children with hypothyroidism. Larger studies are needed to document if the change in the timing of levothyroxine administration to bedtime translates to improved QoL of patients while maintaining an effective control of hypothyroidism. 


\section{References}

1. Hanley P, Lord K, Bauer AJ. Thyroid Disorders in Children and Adolescents: A Review. JAMA Pediatr 2016; 170: 1008-1019. doi: 10.1001/jamapediatrics.2016.0486.

2. Dayal D, Prasad R. Congenital hypothyroidism: Current perspectives. Res Rep Endocr Disord 2015; 5: 91-102. https://doi. org/10.2147/RRED.S56402.

3. Delvecchio M, Salerno M, Vigone MC, et al. Levothyroxine requirement in congenital hypothyroidism: a 12-year longitudinal study. Endocrine 2015; 50: 674-680. doi: 10.1007/s12020-015-0574-1.

4. Cannavò L, Aversa T, Corica D, et al. In children with acquired hypothyroidism levothyroxine requirements may be significantly conditioned by the etiology of thyroid failure. Endocrine 2020; 67: 252-255. doi: 10.1007/s12020-019-01965-2.

5. Skelin M, Lucijanić T, Amidžić Klarić D, et al. Factors Affecting Gastrointestinal Absorption of Levothyroxine: A Review. Clin Ther 2017; 39: 378-403. doi: 10.1016/j.clinthera.2017.01.005.

6. Léger J, Olivieri A, Donaldson M, et al. European Society for Paediatric Endocrinology consensus guidelines on screening, diagnosis, and management of congenital hypothyroidism. Horm Res Paediatr 2014; 81: 80-103. doi: 10.1210/jc.2013-1891.

7. Eck KM, Delaney CL, Clark RL, et al. The "Motor of the Day": Parent and School-Age Children's Cognitions, Barriers, and Supports for Breakfast. Int J Environ Res Public Health 2019; 16: 3238. doi: 10.3390/ijerph16183238.

8. Bauer AJ, Wassner AJ. Thyroid hormone therapy in congenital hypothyroidism and pediatric hypothyroidism. Endocrine 2019; 66: 51-62. doi: 10.1007/s12020-019-02024-6.

9. Nagy EV, Perros P, Papini E, et al. New formulations of levothyroxine in the treatment of hypothyroidism: trick or treat? Thyroid 2021; 31 : 193-201. doi: 10.1089/thy.2020.0515.

10. Dayal D, Saini L, Attri SV, et al. Daily versus alternate day thyroxine therapy to maintain euthyroidism in children with congenital hypothyroidism. Int J Endocrinol Metab 2013; 11: e9499. doi: 10.5812/ ijem.9499.

11. Geer M, Potter DM, Ulrich H. Alternative schedules of levothyroxine administration. Am J Health Syst Pharm 2015; 72: 373-377. doi: 10.2146/ajhp140250.

12. Dayal $D$. Bedtime levothyroxine administration is an attractive option for children with hypothyroidism. Int J Contemp Pediatr. 2018; 5: 684-685. doi: 10.18203/2349-3291.ijcp20180584

13. Akın O. Morning vs. bedtime levothyroxine administration: what is the ideal choice for children? J Pediatr Endocrinol Metab 2018; 31 : 1249-1255. doi: 10.1515/jpem-2018-0168.

14. Elliott DP. Effect of levothyroxine administration time on serum TSH in elderly patients. Ann Pharmacother 2001; 35: 529-532. doi: 10.1345/aph.10286.

15. Pang X, Pu T, Xu L, Sun R. Effect of I-thyroxine administration before breakfast vs at bedtime on hypothyroidism: A meta-analysis. Clin Endocrinol (Oxf) 2020; 92: 475-481. doi: 10.1345/aph.10286.
16. Radhakrishnan R, Venkatasamy S, Pyarejan KS, Jayachandran K. Effectiveness of bedtime levothyroxine intake as compared to morning levothyroxine intake in children. Int J Contemp Pediatr 2017; 4: 1969-1974. doi: 10.18203/2349-3291.ijcp20174155.

17. Bach-Huynh TG, Nayak B, Loh J, et al. Timing of levothyroxine administration affects serum thyrotropin concentration. J Clin Endocrinol Metab 2009; 94: 3905-3912. doi: 10.1210/jc.2009-0860.

18. Ala S, Akha O, Kashi Z, et al. Dose administration time from before breakfast to before dinner affect thyroid hormone levels? Caspian J Intern Med 2015; 6: 134-140.

19. Bruno R, Aversa T, Catena M, et al. Even in the era of congenital hypothyroidism screening mild and subclinical sensorineural hearing loss remains a relatively common complication of severe congenital hypothyroidism. Hear Res 2015; 327: 43-47. doi: 10.1016/j. heares.2015.04.018.

20. Tropeano A, Roszkowska AM, Aversa T, et al. Ocular morphology development and function in children with congenital hypothyroidism diagnosed by neonatal screening. Endocrine 2020. doi: 10.1007/s12020-020-02457-4.

21. Moore JG, Englert E Jr. Circadian rhythm of gastric acid secretion in man. Nature 1970; 226: 1261-1262. doi: 10.1038/2261261a0.

22. Tanguay M, Girard J, Scarsi C, et al. Pharmacokinetics and comparative bioavailability of a levothyroxine sodium oral solution and soft capsule. Clin Pharmacol Drug Dev 2019; 8: 521-528. doi: 10.1002/cpdd.608.

23. Targher G, Montagana M, Salvagno G, et al. Association between serum TSH, free T4 and serum liver enzyme activities in a large cohort of unselected outpatients. Clin Endocrinol (Oxf) 2008; 68: 481-484. doi: 10.1111/j.1365-2265.2007.03068.x.

24. Silva Nde O, Ronsoni MF, Colombo Bda S, et al. Clinical and laboratory characteristics of patients with thyroid diseases with and without alanine aminotransferase levels above the upper tertile cross-sectional analytical study. Arch Endocrinol Metab 2016; 60: 101-107. doi: 10.1590/2359-3997000000066.

25. Asvold BO, Vatten LJ, Nilsen TI, Bjøro T. The association between TSH within the reference range and serum lipid concentrations in a population-based study. The HUNT Study. Eur J Endocrinol 2007; 156: 181-186. doi: 10.1530/eje.1.02333.

26. Alamdari S, Amouzegar A, Tohidi M, et al. Hypothyroidism and Lipid Levels in a Community Based Study (TTS). Int J Endocrinol Metab 2015; 14: e22827. doi: 10.5812/ijem.22827.

27. Tenneti N, Dayal D, Sharda S, et al. Concentrations of leptin, adiponectin and other metabolic parameters in non-obese children with Down syndrome. J Pediatr Endocrinol Metab 2017; 30: 831-837. 0.1515/jpem-2016-0422

28. Iglesias P, Bajo MA, Selgas R, Díez JJ. Thyroid dysfunction and kidney disease: An update. Rev Endocr Metab Disord 2017; 18 : 131-144. doi: 10.1007/s11154-016-9395-7.

29. Dayal D, Gupta S, Raithatha D, Jayashree M. Missing during COVID-19 lockdown: Children with onset of type 1 diabetes. Acta Paediatr 2020; 109: 2144-2146. doi: 10.1111/apa.15443. 